\title{
PERAN KADER ALIANSI PITA PUTIH INDONESIA DALAM PEMBERDAYAAN KESEHATAN IBU DAN BAYI (STUDI KASUS GERAKAN SAYANG IBU DESA PAIT KASEMBON MALANG)
}

\author{
Hidayatul Mashfiyah, Endang Sri Redjeki, Ishom \\ Universitas Negeri Malang, Jalan Semarang 5 Malang 65145 \\ E-mail: hidaendut@yahoo.com
}

\begin{abstract}
This The aim of this research is to know how the role of APPI cadre is in their effort to empower mothers and baby's health. This research uses qualitative approach with research type of a case study. Data collection technique in this research includes observation, interview, and documentation. To keep data valid, credibility test with observation advanced and data triangulation is conducted. Data analysis started from data reduction, data display, and conclusion drawing. The results of this research are that APPI cadre role in their efforts to empower people to the KIBBLa program as follow: instructor or informant, motivator, training tutor and as resource linker.
\end{abstract}

Keywords: APPI cadre role, the empowerment of mothers and baby's health

\begin{abstract}
Abstrak: Tujuan penelitian ini yaitu untuk mengetahui bagaimana peran kader APPI dalam upaya pemberdayaan kesehatan ibu dan bayi. Penelitian ini menggunakan pendekatan kualitatif, dengan jenis penelitian studi kasus. Teknik pengumpulan data menggunakan observasi, wawancara, dan dokumentasi. Untuk menjaga keabsahan data, dilakukan uji credibility. Analisis data dimulai dari reduksi data, display data, dan menarik kesimpulan. Hasil penelitian menunjukkan bahwa peran kader (APPI) dalam pemberdayaan masyarakat pada program KIBBLa adalah: penyuluh atau informan, motivator, tutor, dan penghubung sumber (resource linker).
\end{abstract}

Kata kunci: peran kader APPI, pemberdayaan kesehatan ibu dan bayi

Dewasa ini ketidakberdayaan masyarakat dalam problem solving (mengatasi permasalahan) baik permasalahan individual maupun masalah kelompok menjadi hal yang biasa di masyarakat, jika dikaji secara mendalam keadaan ketidakberdayaan itu perlu diatasi agar tidak terjadi kesenjangan sosial. Mengatasi masalah ketidakberdayaan masyarakat yaitu dengan memberdayakan. Rasyad (2003) mendefinisikan pemberdayaan dilihat dari asal kata pemberdayaan (empowerment) dan memberdayakan (empower) berarti memberikan kekuasaan, mengalihkan kekuatan atau mendelegasikan otoritas ke pihak lain dan sebagai upaya untuk memberi kemampuan atau keberdayaan. Dalam penelitian ini peneliti membahas ketidakberdayaan masyarakat dalam bidang kesehatan khususnya dalam menghadapi kasus kematian ibu dan bayi pada saat mengandung, melahirkan, masa nifas dan bayi baru lahir. Deputi Bidang Keluarga Sejahtera dan Pemberdayaan Keluarga (KSPK) BKKBN Sudibyo dalam pertemuan ulama Kalimantan Selatan di Banjarmasin menyatakan penelitian tentang kualitas penduduk Indonesia 2011 tercatat Angka Kematian Ibu (AKI) masih sebesar 228/100.000 kelahiran hidup. Selanjutnya angka kematian bayi usia 0 s.d. 11 bulan Angka Kematian Bayi (AKB) adalah 34 per 1.000 kelahiran hidup.

Berbagai program yang gencar dilakukan pemerintah dalam bidang kesehatan dan pembentukan organisasi yang bekerjasama antara pemerintah dengan kader kesehatan saat ini adalah organisasi Aliansi Pita Putih Indonesia (APPI) yang bertujuan menekan AKI dan AKB. APPI di Desa Pait didirikan pada tahun 2011 yang diketuai oleh Sriyono yang merupakan Sekretaris Desa. Pendidikan Luar Sekolah (PLS) merupakan 
meningkatkan dan mengembangkan sumber daya manusia, agar memiliki pengetahuan, ketrampilan, sikap dan daya saing untuk merebut peluang yang tumbuh dan berkembang, dengan mengoptimalkan penggunaan sumber-sumber yang ada di lingkungan (Sihombing, 2000). Peran kader APPI pada program KIBBLa dalam upaya pemberdayaan kesehatan ibu dan bayi, menurut APPI dan Pusat Promkes Kemenkes (2011) yaitu sistem informasi atau penyuluhan, sistem transportasi, sistem donor darah, sistem tabulin (tabungan ibu bersalin).

Kaitan Peran kader APPI dalam PLS yaitu membantu masyarakat khususnya kaum ibu dan bayi untuk mendapatkan informasi atau penyuluhan, pelayanan kesehatan yang layak dengan menjadi fasilitator kesehatan. Hal ini juga sesusuai dengan tipe program PLS. Faisal (2007) menyatakan tipe program PLS yaitu informasional (semacam penyuluhan), institusional (semacam kursus, penataran, pelatihan), dan developmental (pengembangan). Fokus kaitan peran kader dengan tipe program PLS developmental (pengembangan) atau bisa juga disebut pemberdayaan. Menurut hasil penelitian sebelumnya yang diteliti oleh Sistiarani, dkk., (2013) dipaparkan kader posyandu terkait dengan pelaksanaan program KIA (Kesehatan Ibu dan Anak) memegang peranan penting dalam menggerakkan keaktifan ibu dalam peningkatan kesehatan ibu dan anak. Penelitian ini untuk mengetahui faktor yang berhubungan dengan peran kader dalam penggunaan buku KIA di kecamatan Kalibagor, peningkatan pengetahuan kader dalam penggunaan buku KIA, sosialisasi penggunaan buku KIA, pemanfaatan buku KIA sebagai media KIE, pemahaman mengenai peran kader dalam melakukan pengecekan kelengkapan isian buku KIA setiap ibu dalam kegiatan posyandu.

Berdasarkan konteks penelitian, prestasi dan keberlanjutan program GSI di Desa Pait dalam memberdayakan kesehatan ibu dan bayi agar terhindar dari kasus AKI dan AKB, maka peneliti tertarik untuk meneliti lebih lanjut mengenai peran kader APPI dalam pemberdayaan kesehatan ibu dan bayi pada program KIBBLa (Studi Kasus Gerakan Sayang Ibu di Desa Pait Kasembon Malang). Penelitian ini bertujuan untuk mengetahui bagaimana peran kader sebagai penyuluh atau informan, sebagai motivator, sebagai pelatih, sebagai pengubung sumber (resource linker).

\section{METODE}

Peneliti menggunakan pendekatan penelitian kualitatif. Jenis penelitiannya menggunakan studi kasus. Studi kasus dalam penelitian ini adalah Gerakan Sayang Ibu di Desa Pait Kasembon Malang. Kehadiran peneliti dalam penelitian ini sangat berpengaruh hal ini dikarenakan peneliti merupakan instrument utama selama pengumpulan data. Kegiatan penelitian ini dilaksanakan di Desa Pait Kecamatan Kasembon Kabupaten Malang. Dalam penelitian ini sumber data atau subjek atau partisipan risetnya yaitu Kader APPI dan Masyarakat Sasaran APPI yang ada di Desa Pait Kecamatan Kasembon Kabupaten Malang. Prosedur pengumpulan data yang digunakan peneliti yaitu wawancara, observasi dan dokumentasi, hal ini dilakukan oleh peneliti karena setiap teknik mempunyai keterbatasan dalam mengumpulkan data dan agar peneliti mendapatkan data yang akurat.

Analisis data pada penelitian ini yaitu proses pengolaan data yang telah terkumpul berdasarkan temuan observasi, dokumentasi dan wawancara untuk dijadikan suatu deskripsi guna meningkatkan pemahaman terkait peran kader APPI dalam upaya pemberdayaan kesehatan ibu dan bayi pada program KIBBLa. Miles dan Huberman analisis data terdiri dari tiga tahap, yaitu data reduction atau reduksi data, data display, conclusion drawing/verification (Sugiyono, 2009). Pengecekan keabsahan penelitian ini menggunakan perpanjangan pengamatan dan triangulasi. Tahaptahap penelitian ini yaitu tahap pra penelitian pada bulan November, penyelenggaraan penelitian bulan Desember pada minggu ke-2 dan tahap pasca penelitian.

\section{HASIL}

Desa Pait merupakan desa yang terletak di Propinsi Jawa Timur, Kecamatan Kasembon, Kabupaten Malang. Sebelahutara Desa Wonoagung, sebelah timur Kecamatan Ngantang, sebelah barat Desa Wonoagung. Tabel 1 tersaji Organisasi Kesehatan di Desa Pait. Keberlangsungan organisasi dan program kesehatan di Desa Pait perlu mendapatkan perhatian khusus oleh lembaga maupun pemerintahan terkait, hal ini dikarena tidak semua Desa melaksanakan dan meneruskan 
program pemerintah dalam menekan AKI dan AKB, sehingga dengan perhatian khusus inilah diharapkan dapat menjadikan contoh desa lain yang masih ditemukan AKI dan AKB.

Tabel 1 Organisasi Kesehatan Desa Pait

\begin{tabular}{cll}
\hline No & \multicolumn{1}{c}{ Nama Organisasi } & \multicolumn{1}{c}{ Tahun } \\
\hline 1 & GSI & 1996 \\
2 & Desa Siaga & $2006 / 2007$ \\
3 & KIBBLa & 2010 \\
4 & Revitalisasi GSI & 2010 \\
5 & APPI & 2011 -sekarang \\
\hline
\end{tabular}

Tabel 2 Data Bumil, Bulin/Bufas, dan Bayi Lahir Desa Pait

\begin{tabular}{cccc}
\hline No & Tahun & $\begin{array}{c}\text { Bumil Bulin / } \\
\text { Bufas }\end{array}$ & Bayi Lahir \\
\hline 1 & 2008 & $95-89$ & 89 \\
2 & 2009 & $91-84$ & 84 \\
3 & 2010 & $90-83$ & 83 \\
4 & 2011 & $86-78$ & 78 \\
5 & 2012 & $86-83$ & 83 \\
6 & 2013 & $86-75$ & 75 \\
\hline
\end{tabular}

Tabel 2 dipaparkan terjadi penurunan bumil, bulin/bufas dan bayi lahir di tahun 2008-2011, akan tetapi tahun 2012 terjadi kenaikan dan kembali menurun di tahun 2013. Berbagai alasan yang dikemukakan kader APPI dalam bergabung menjadi kader. Seperti halnya yang dikemukakan oleh Anggota Kader yang merupakan kader yang masa baktinya 23 tahun yang mendapat penghargaan dari Dinas Kesehatan, karena: (1) orang tua yang dulunya sebagai aktivis di desa menjadikan motivasi untuk bergabung menjadi kader kesehatan sampai saat ini; dan (2) bisa membantu masyarakat melalui pikiran dan tenaga.

Peran kader dalam penyuluhan dilakukan di dua tempat yaitu di tetangga sekitar tempat tinggal kader dan bertempat di Posyandu dan Poskesdes. Penyuluhan pada tempat tinggal kader dilakukan karena disetiap RT terdapat kader seperti jargon desa Pait yaitu one RT one Kader dan saat ini jumlah kader tidak hanya satu di setiap RT akan tetapi lebih, dimana masing-masing kader memiliki tanggung jawab dan kewajiban menyampaikan informasi kesehatan khususnya dalam menekan AKI dan AKB di Desa Pait. Penyuluhan di Posyandu di laksanakan 1 bulan 1 kali dan penyuluhan di Poskesdes setiap ibu, balita dan keluarga saat melakukan pemeriksaan.

Peran kader dalam pemberian motivasi dilakukan dengan berbagai cara, atara lain dengan mendatangi rumah-rumah (door to door) dan ketika pihak sasaran melakukan pemeriksaan atau pengecekan kesehatan yang dilakukan setiap bulan, pada saat itulah kader memberikan dorongan, penguatan untuk psikologis pihak sasaran. Peran kader dalam pelatihan yang diberikan kader antara lain pemberian pelatihan bermacam-macam seperti pemberian pelatihan pembuatan makanan sehat untuk anak, senam ibu hamil, mendeteksi kekurangan gizi anak dan deteksi kesehatan ibu hamil dalam bahaya.

Peran kader sebagai penghubung sumber (resource linker) yaitu menghubungkan sistem transportasi, donordarah dan dana kelahiran (tabulin dan dasolin). Pertama, Sebagai penghubung sistem transportasi. Kedua, sebagai penghubung donor darah. Ketiga, sebagai penghubung dana kelahiran (Dasolin (dana sosial ibu bersalin) dan Tabulin (tabungan ibu bersalin). Berdasarkan studi dokumentasi dana kelahiran Dasolin dikeluarkan oleh warga secara sukarela.

\section{PEMBAHASAN}

Kader APPI merupakan agen pembaru masyarakat. Peran agen pembaru (change agent) menurut Schwartz dalam Wrihatnolo (2007) yaitu: (1) catalisator, memberi informasi penting dalam mememcahkan masalah yang dihadapi klien; (2) dinamisator, membangkitkan semangat klien untuk mengatasi masalah yang dihadapi; (3) solution giver, memberikan saran, alternatif yang ditawarkan kepada klien; (4) procces helper, membantu klien dalam menjalankan proses pemecahan; dan (5) resource linker, menghubungkan sumber-sumber yang dibutuhkan klien.

\section{Peran Kader sebagai Penyuluh}

Peran kader sebagai penyuluhan yaitu proses penyadaran masyarakat sasaran khususnya dalam bidang kesehatan dengan memberikan informasi-informasi guna menambah pengetahuan dan harapannya bisa diimplementasikan pada kehidupan sehari-hari. Peran kader dalam penyuluhan dilakukan di dua tempat yaitu di tetangga sekitar tempat tinggal kader dan bertempat di Posyandu dan Poskesdes. Peran kader dalam penyuluhan memberikan pendidikan kepada 
masyarakat. Pendidikan dalam pandangan fungsi sebagai pembentukan pribadi yaitu sebagai suatu kegiatan yang sistematis terarah terbentuknya kepribadian peserta didik (Tirtarahardja, 2005). Proses pendidikan yang terjadi dalam penyuluhan terjadi suatu perubahan tingkahlaku. Hal ini terlihat bahwa pendidikan tersebut bersifat transformatif. Moedzakir (2010) menyatakan pembelajaran atau pendidikan yang transformatif adalah pembelajaran atau pendidikan yang menghasilkan perubahan mendasar pada peserta didik.

Kaitan antara penyuluhan dan pemberdayaan merupakan konsep yang memiliki tujuan sama yaitu membuat klien atau sasaran menjadi berdaya. Slamet (1992) menyatakan pemberdayaan masyarakat adalah ungkapan lain dari tujuan penyuluhan pembangunan. Pemberdayaan dalam aktivitas penyuluhan ini bertahap pada proses penyadaran dengan tujuan memberikan peluang bagi masyarakat sasaran program untuk menjelajahi situasi mereka dan struktur serta wacana yang menindas kehidupan sehingga mereka sadar. Pemberdayaan inilah yang merupakan salah satu aktivitas PLS, yaitu kaum tertinggal. Kaum tertinggal dimaksudkan disini adalah ketertinggalan dari informasi kesehatan khususnya kesehatan dalam mengandung, melahirkan, nifas dan bayi baru lahir.

\section{Peran Kader sebagai Motivator}

Mc.Donald menyatakan motivasi adalah perubahan energi dalam diri seseorang yang ditandai dengan munculnya feeling atau perasaan dan didahului dengan tanggapan terhadap adanya tujuan (Sardiman, 2011). Peran kader sebagai pemberi motivasi yaitu pemberian dorongan kepada masyarakat sasaran, dorongan yang diberikan berupa penguatan terhadap kehamilan, memperhatikan kesehatan ibu dan bayi. Aktivitas kader dalam pemberian motivasi dilakukan dengan berbagai cara, atara lain dengan mendatangi rumah-rumah (door to door) dan ketika pihak sasaran melakukan pemeriksaan atau pengecekan kesehatan yang dilakukan setiap bulan, pada saat itulah kader memberikan dorongan, penguatan untuk psikologis pihak sasaran.

Pemberian motivasi yang dilakukan kader merupakan jenis motivasi ekstrinsik. Dimyati (2006) menyatakan motivasi ekstrinsik yaitu dorongan terhadap perilaku seseorang yang ada diluar perbuatan yang dilakukannya. Orang berbuat sesuatu, karena dorongan dari luar seperti adanya hadiah dan menghindari hukuman. Kaitan antara motivasi dan pemberdayaan merupakan konsep yang memiliki tujuan sama yaitu membuat klien atau sasaran menjadi berdaya. Pemberdayaan dalam aktivitas motivasi ini bertahap pada proses penguatan dengan tujuan memberikan peluang bagi masyarakat sasaran program untuk menjelajahi situasi mereka dan struktur serta wacana yang menindas kehidupan sehingga mereka sadar, memulai untuk memikirkan masalah yang dihadapi dan kebutuhannya.

\section{Peran Kader sebagai Pelatih}

Flippo menyatakan bahwa training is the act of increasing the knowledge and skill of an employee for doing a particular job (Kamil, 2010). Pelatihan adalah tindakan meningkatkan pengetahuan dan ketrampilan seorang pegawai untuk melaksanakan pekerjaan tertentu. Peran kader sebagai pelatihan adalah meningkatkan pengetahuan dan ketrampilan masyarakat sasaran untuk dapat menjaga kesehatan yang lebih optimal. Pelatihan yang diberikan kader antara lain pemberian pelatihan bermacam-macam seperti pemberian pelatihan pembuatan makanan sehat untuk anak, senam ibu hamil, mendeteksi kekurangan gizi anak dan deteksi kesehatan ibu hamil dalam bahaya. Hasil studi dokumentasi pelatihan yang dilakukan kader antara lain pembuatan snack, makanan sehat dan senam ibu hamil, hal ini juga sesuai dengan hasil observasi dilapangan.

Pelatihan pada umumnya memiliki tujuan, salah satunya dalam rangka pemberdayaan. Kamil (2010) menyatakan tujuan pelatihan dalam rangka pemberdayaan adalah untuk mempersiapkan anggota masyarakat agar mempunyai kemampuan profesional, dan kompetensi yang bermutu dan relevan dengan kebutuhan hidupnya atau pekerjaan yang sedang digelutinya. Pemberdayaan dalam aktivitas pelatihan ini bertahap pada proses penguatan dengan tujuan memberikan peluang bagi masyarakat sasaran program untuk menjelajahi situasi mereka dan struktur serta wacana yang menindas kehidupan sehingga mereka sadar, memulai untuk memikirkan masalah yang dihadapi, kebutuhannya dan sudah mulai 
melakukan tindakan. Pemberdayaan inilah yang merupakan salah satu aktivitas PLS, yaitu kaum tertinggal. Kaum tertinggal dimaksudkan disini adalah ketertinggalan dari ketrampilan guna menjaga kesehatan khususnya kesehatan dalam mengandung, melahirkan, nifas dan bayi baru lahir.

\section{Peran Kader sebagai Penghubung Sumber (Resource Linker)}

Schwartz menyatakan penghubung sumber (resource linker) yaitu menghubungkan sumbersumber yang dibutuhkan klien (Wrihatnolo, 2007). Peran kader sebagai penghubung sumber yaitu penghubung sistem transportasi, donor darah, dan dana kelahiran (tabulin dan dasolin). Sebagai penghubung sistem transportasi, peran kader APPI sebagai penghubung sistem transportasi ibu saat melahirkan yaitu kader menghubungkan antara ibu hamil atau keluarga dengan transportasi saat melahirkan. Kader menghubungkan ibu hamil atau keluarga dengan warga yang mempunyai mobil pribadi, hal ini bertujuan untuk mencegah keterlambatan datangnya ambulan desa. Warga yang memiliki mobil pribadi diajak oleh kader untuk berpartisipasi dengan meminjamkan kendaraan dengan diberikan surat pernyataan. Alasan kader memberikan pelayanan sebagai penghubung transportasi yaitu karena keterbatasan atau ketakberdayaan masyarakat sasaran dalam mencari transportasi secara cepat dan mudah.

Sebagai penghubung donor darah, yaitu seorang kader menghubungkan anatara ibu hamil dengan pendonor darah. Hal ini dilakukan oleh kader untuk mencegah terjadinya kekurangan darah oleh ibu saat melahirkan serta karena keterbatasan atau ketakberdayaan masyarakat sasaran dalam mencari pendonor secara cepat dan mudah. Pendonor diusahakan dari pihak keluarga, jika tidak ada barulah masyarakat. Sebagai penghubung sumber dana kelahiran (Dasolin dan Tabulin). Dasolin saat ini tidak lagi secara sukarela dari warga masyarakat, melainkan di ambilkan dari uang kas sembako. Sedangkan untuk Tabulin saat ini masih berjalan, hal ini dikarenakan masyarakat sudah cukup sadar dengan tabungan yang dibutuhkan saat melahirkan. Bentuk tabulin tidak harus berupa uang bisa juga benda seperti hewan ternak, emas, sepeda dan lain sebaginya yang bisa dijual.
Hikmat (2006) menyatakan proses pemberdayaan mengandung dua kecenderungan, yaitu: pertama, proses pemberdayaan yang menekankan pada proses memberikan atau mengalihkan sebagai kekuasaan, kekuatan, atau kemampuan kepada masyarakat agar individu yang bersangkutan menjadi lebih berdaya (survival of the fittes). Jika dikaitkan dengan praktik pemberdayaan yang diperankan kader APPI, maka proses pemberdayaan ini sama dengan peran kader dalam pelatihan yang memiliki tujuan dalam mengalihkan kemampuan kepada masyarakat sasaran dalam menjaga kesehatan. Kedua, pada proses menstimulasi, mendorong, atau memotivasi agar individu mempunyai kemampuan atau keberdayaan untuk menentukan apa yang menjadi pilihan hidupnya melalui proses dialog. Jika dikaitkan dengan praktik pemberdayaan yang diperankan kader APPI proses pemberdayaan ini sama dengan peran kader dalam penyuluhan dan motivasi, pada proses menstimulasi, mendorong, atau memotivasi agar individu mempunyai kemampuan atau keberdayaan dalam menjaga kesehatan supaya terhindar dari AKB dan AKI.

\section{SIMPULAN DAN SARAN}

\section{Simpulan}

Peran kader sebagai penyuluhan yaitu proses penyadaran masyarakat sasaran khususnya dalam bidang kesehatan dengan memberikan informasi-informasi guna menambah pengetahuan dan harapannya bisa diimplementasikan pada kehidupan sehari-hari. Materi penyuluhan di Desa Pait yang diberikan kader bervariasi, seperti Akibat BGM dan Gizi Buruk, penanggulangan diare dan vitamin A, TBC, PMT bagi ibu hamil dan balita, macam-macam KB, macam-macam dan manfaat imunisasi bagi balita, PMT bumil dan balita. Lebih lengkapnya lihat pada lampiran 11 (Sumber dokumen materi penyuluhan).

Peran kader sebagai pemberi motivasi yaitu pemberian dorongan kepada masyarakat sasaran, dorongan yang diberikan berupa penguatan terhadap kehamilan, memperhatikan kesehatan ibu dan bayi. Aktivitas kader dalam pemberian motivasi dilakukan dengan berbagai cara, atara lain dengan mendatangi rumah-rumah (door to door) dan ketika pihak sasaran melakukan pemeriksaan 
atau pengecekan kesehatan yang dilakukan setiap bulan, pada saat itulah kader memberikan dorongan, penguatan untuk psikologis pihak sasaran. Selain itu motivasi diberikan dengan cara mengorganisir arisan yang dikeluarkan setiap acara pemeriksaan dan pengecekan di setiap bulannya, tiap nama membayar Rp. 5.000.

Peran kader sebagai pelatihan adalah meningkatkan pengetahuan dan ketrampilan masyarakat sasaran untuk dapat menjaga kesehatan yang lebih optimal. Pelatihan yang diberikan kader antara lain pemberian pelatihan bermacam-macam seperti pemberian pelatihan pembuatan makanan sehat untuk anak, senam ibu hamil, mendeteksi kekurangan gizi anak dan deteksi kesehatan ibu hamil dalam bahaya. Peran kader sebagai penghubung sumber yaitu penghubung sistem transportasi, donor darah dan dana kelahiran (tabulin dan dasolin). Pertama, sebagai penghubung sistem transportasi. Kedua, sebagai penghubung donor darah. Ketiga, sebagai penghubung sumber dana kelahiran (Dasolin dan Tabulin).

\section{Saran}

Bagi organisasi APPI di Desa Pait sebaiknya selalu memacu kader untuk berperan lebih aktiv dalam peran pemberdayaan kesehatan guna mempertahankan prestasi juara 1 Jawa Timur sebagai Desa Sayang Ibu 2010. Bagi jurusan PLS hendaknya memberikan dorongan kepada mahasiswa untuk memperoleh gambaran praktik pemberdayaan masyarakat di lapangan yang lebih banyak. Dengan demikian mahasiswa berpeluang menjadi kreatif dan menjadi lulusan yang siap kerja. Bagi mahasiswa PLS Dari penelitian ini mahasiswa diharapkan dapat mengambil pelajaran bagaimana peran kader dalam upaya pemberdayaan, sehingga dapat menambah wawasan kedepan.

\section{DAFTAR RUJUKAN}

Aliansi Pita Putih Indonesia \& Pusat Promkes Kementerian Kesehatan. 2011. Program Keselamatan Ibu dan Bayi Baru Lahir (KIBBLA). Jakarta: Kementerian Kesehatan.

Dimyati. 2006. Belajar dan Pembelajaran. Jakarta: PT Rineka Cipta.
Faisal, S. 2007. Pendidikan Luar Sekolah Tugas Mulia Mengisi Pembangunan. Jakarta: Direktorat Pendidikan Masyarakat, Direktorat Jenderal Pendidikan Nonformal dan Informal, Departemen Pendidikan Nasional.

Hikmat, H. 2006. Strategi Pemberdayaan Masyarakat. Bandung: Humaniora.

Kamil. 2010. Model Pendidikan dan Pelatihan (Konsep dan Aplikasi). Bandung: Alfabeta.

Moedzakir, D. M. 2010. Metode Pembelajaran untuk Program-program Pendidikan Luar Sekolah. Malang: UM Press.

Wrihatnolo, R. R., \& Dwidjowijoto, N. R. 2007. Manajemen Pemberdayaan (Sebuah Pengantar dan Panduan untuk Pemberdayaan Masyarakat). Jakarta: PT Elex Media Komputindo.

Rasyad, B., \& Suparna. 2003. Pengembangan dan Pemberdayaan Masyarakat. Malang: UM Press.

Sadirman. 2011. Interaksi dan Motivasi Belajar Mengajar. Jakarta: PT RajaGrafindo Persada.

Sihombing, U. 2000. Pendidikan Luar Sekolah Manajemen Strategi. Tanpa Kota: PD Mahkota.

Sistiarani, C., Nurhayati, S., \& Suratman. 2013. Faktor yang Mempengaruhi Peran Kader dalam Penggunaan Buku Kesehatan Ibu dan Anak. Jurnal Kesehatan Masyarakat, 8(2): 77-84.

Sugiyono. 2009. Metode Penelitian Kuantitatif dan Kualitatif. Bandung: Alfabeta.

Slamet, M. 1992. Perspektif Ilmu Penyuluhan Pembangunan Menyongsong Era Tinggal Landas. Jakarta: Pustaka Pembangunan Swadaya Nusantara.

Sugiyono. 2009. Metode Penelitian Kuantitatif, Kualitatif dan $R \& D$. Bandung: Alfabeta.

Tirtarahardja, U., \& Sulo, L. S. 2005. Pengantar Pendidikan. Jakarta: PT Rineka Cipta. 